\title{
Early gait analysis after curved periacetabular osteotomy for acetabular dysplasia
}

\author{
This article was published in the following Dove Press journal: \\ Orthopedic Research and Reviews \\ 17 February 2015 \\ Number of times this article has been viewed
}

\section{Masamichi Nishimura' \\ Naonobu Takahira ${ }^{1-3}$ \\ Kensuke Fukushima ${ }^{3,4}$ \\ Takeaki Yamamoto ${ }^{4}$ \\ Mitsutoshi Moriya ${ }^{4}$ \\ Katsufumi Uchiyama ${ }^{4}$ \\ 'Graduate School of Medical Science, Kitasato University, ${ }^{2}$ Department of Rehabilitation, Kitasato University School of Allied Health Sciences, ${ }^{3}$ Department of Orthopaedic Surgery, Kitasato East Hospital, ${ }^{4}$ Department of Orthopaedic Surgery, Kitasato University School of Medicine, Kanagawa, Japan}

Correspondence: Masamichi Nishimura Graduate School of Medical Science, Kitasato University, I-I5-I Kitasato, Minamiku, Sagamihara, Kanagawa 252-0373, Japan Tel +8I 0427789305 Email masamichi.nishimura@kyobun.ac.jp; nishimura2244@yahoo.co.jp
Purpose: The objective of the study was to prospectively investigate the characteristics of gait among patients before and soon after curved periacetabular osteotomy (CPO) in comparison with healthy subjects.

Subjects and methods: The subjects were six patients who underwent CPO and six healthy adults. Gait analysis was performed before surgery and at an average of 7.3 months after surgery using a three-dimensional motion analysis system. Temporospatial factors (gait velocity and stride length) and kinematic factors (range of motion of the hip joint in the sagittal plane, and ranges of tilting movement of the trunk and of the pelvic region in the coronal plane) were evaluated.

Results: Gait velocity increased after surgery, but it was significantly lower than that of the healthy group $(P<0.05)$. Stride length significantly increased after surgery compared to before surgery $(P<0.05)$, though the significant difference seen before surgery disappeared. The full range of motion of the hip joint in the sagittal plane during walking increased after surgery, though the significant difference evident between the two groups before surgery also disappeared. The range of tilting movement of the trunk during walking increased after surgery, with a significant difference emerging when compared to the healthy group, which was not observed before surgery $(P<0.05)$.

Conclusion: The characteristics of gait were investigated in patients treated with CPO before and after surgery, and compared with those in healthy subjects. Gait improved, except for sway of the trunk while walking, despite the analysis being performed soon after surgery.

Keywords: curved periacetabular osteotomy, gait analysis, range of motion of the hip joint, range of tilting movement of the trunk

\section{Introduction}

Developmental dysplasia of the hip (DDH) is responsible for $80 \%$ of cases of secondary osteoarthritis of the hip in Japan. ${ }^{1-3}$ In DDH, lateralization of the center of the hip joint occurs due to insufficient coverage of the femoral head by the acetabulum, a reduction of the weight-bearing area of the acetabulum, and an increase in the hip joint contact pressure, which induces degenerative changes in cartilage in the early phase. ${ }^{4-8}$ This harmful mechanical condition results in dysfunction, such as coxalgia and claudication, which then progresses to secondary osteoarthritis of the hip..$^{9-14}$

Periacetabular osteotomy (PAO) to improve functional-morphological disorders in DDH patients was proposed by Ganz and has been widely performed for many years. ${ }^{15}$ This procedure has anatomical aims of increasing coverage by the acetabula and dispersing the hip joint contact pressure by leveling the weight-bearing 
acetabular (AC) surface; it also has clinical aims of pain relief and functional improvement of the hip joint, prevention of progression to osteoarthritis of the hip, and delaying or avoiding the need for total hip arthroplasty (THA). ${ }^{6,15-21}$ Favorable outcomes of PAO have been reported, ${ }^{16,22-25}$ but there is also a high incidence of complications, including sympathetic dystrophy due to extensive exposure of the surgical field during surgery, motor paralysis, delayed union in the iliac region, hemorrhage, and ectopic ossification. $^{21,25-27}$

In 2005, Naito et $\mathrm{al}^{28}$ reported curved PAO (CPO) as a new surgical method for DDH. CPO has subsequently been found to yield favorable results in radiographic and clinical functional evaluations. ${ }^{28,29}$ Gait disorders represented by Trendelenburg claudication and Duchenne claudication are physical dysfunctions common to many patients with hip joint diseases, including DDH. ${ }^{30,31}$ Following surgery, patients have a strong desire for functional improvement of gait disorders, such as claudication, and pain relief in the hip joint. Gait analysis is widely performed in patients with hip joint diseases to evaluate walking function quantitatively before and after surgery, ${ }^{32-36}$ but it is mostly performed in THA cases. Only a few gait analyses of patients treated with AC osteotomy have examined treatment with PAO and rotational AC osteotomy (RAO)..$^{34,37,38}$

RAO was described before $\mathrm{CPO}^{39}$ and was originally thought to be advantageous because the contact area of the osteotomy region is widened to improve its fit by adding a curve to the osteotomized surface of the AC roof. However, the surgical approach is invasive to the abductors of the hip joint, as represented by the gluteus medius muscle, because PAO uses an approach from the lateral side of the osteotomy region in RAO compared to that in CPO. In CPO, the procedure of osteotomy of the $\mathrm{AC}$ roof is similar to that in RAO, but it is less invasive to the abductors because an approach from the medial side of the osteotomy region is used. Therefore, it is hypothesized that improvement of preoperative reduced gait ability will be observed in gait analysis soon after CPO.

There have been no reports on gait function after surgery in patients treated with CPO, and the recovery process for temporospatial factors, such as postoperative gait velocity and stride length, and kinematic factors, such as ranges of motion of the hip and trunk tilting movement representing trunk sway during walking, has not been clarified. Therefore, the objective of this study was to prospectively investigate gait in CPO-treated patients before and soon after surgery in comparison with healthy subjects.

\section{Subjects and methods}

The subjects were patients who were diagnosed with DDH at the Orthopaedic Department of Kitasato University East Hospital (Kanagawa, Japan) between 2010 and 2012, and who underwent CPO. The study content was explained orally using documents that were given to all patients scheduled for surgery within this period, and six female patients who gave consent were registered as a surgical group. Six healthy adult volunteers with body compositions that matched those of the surgical group were included in the study as a control group (Table 1). The exclusion criteria were a history of surgery for disorders of the musculoskeletal system, rheumatoid arthritis, osteoarthritis, deformation of the lower limb joints including the hip joint, and diseases involving neuromuscular disorders. Preoperative evaluation was performed on the day before surgery, and postoperative evaluation was performed at an average of 7.3 months after surgery (range: 6.3-9.3 months).

\section{Items in radiographic and clinical functional evaluations}

In the radiographic evaluation, the central-edge angle, sharp angle, AC angle, and AC Head Index were used as indices of the degree of femoral head coverage by the acetabula. In the clinical evaluation, the hip joint function judgment criteria established by the Japanese Orthopaedic Association (JOA) Hip Score and a Visual Analog Scale (VAS) for pain due to coxalgia were used. The JOA Hip Score is widely used in Japan for the evaluation of hip joint disease and includes the following four items: pain (40 points); range of motion (ROM) of the joint (20 points); gait ability (20 points); and activities of daily living (ADL) (20 points). ${ }^{40}$

\section{Gait analysis}

In gait analysis, to measure the ranges of motions of the trunk, pelvic region, and femoral region during walking, a pectoral girdle, pelvic belt, and supporters were attached to the trunk, pelvic region, and thighs, respectively. Three

Table I Demographic data for patients and controls

\begin{tabular}{llll}
\hline & $\begin{array}{l}\text { Patients with } \\
\text { DDH }(\mathbf{n}=6)\end{array}$ & $\begin{array}{l}\text { Controls } \\
(\mathbf{n}=6)\end{array}$ & P-value \\
\hline Age at surgery, years & $36.3 \pm 9.5$ & $37.2 \pm 9.6$ & 0.89 \\
Height $(\mathrm{m})$ & $1.59 \pm 0.08$ & $1.60 \pm 0.06$ & 0.80 \\
Weight $(\mathrm{kg})$ & $59.4 \pm 6.4$ & $60.6 \pm 6.8$ & 0.77 \\
BMl $\left(\mathrm{kg} / \mathrm{m}^{2}\right)$ & $23.7 \pm 3.0$ & $23.4 \pm 2.2$ & 1.00 \\
\hline
\end{tabular}

Note: Values are expressed as the mean $\pm S D$.

Abbreviations: DDH, developmental dysplasia of the hip; n, number; BMI, body mass index; SD, standard deviation. 
reflex markers were affixed to each attachment site (12 markers in total), and the rigid body was defined based on the markers attached to the trunk, pelvic region, and thighs. The rigid body was defined, and marker sites were chosen with reference to previously reported similar methods: the trunk was defined based on the markers affixed to the medial ends of the bilateral scapular spines and spinal spinous process on the line connecting the inferior angles of the bilateral scapulae; the pelvic region was defined based on the markers affixed to the bilateral superior posterior iliac spines and coccygeal region; and the femoral region was defined based on the markers affixed to the inferior portion of the ischial tuberosity, inferior portion of the greater trochanter, and central region of the posterior surface of the thigh. ${ }^{41,42}$ The subjects walked on a $6 \mathrm{~m}$ gait path at a free speed. Using an OptiTrack ${ }^{\mathrm{TM}}$ Motion Capture system (NaturalPoint Inc., Corvallis, OR, USA), the reflex markers were traced during walking and converted to three-dimensional coordinates using six infrared cameras. Joint angles were calculated from the coordinate data using MATLAB ${ }^{\circledR}$ 7.0.1 (The MathWorks, Inc., Natick, MA, USA). From these data, the gait velocity and stride length were evaluated as temporospatial factors, and the ROM of the hip joint in the sagittal plane, and the ranges of tilting movement of the trunk and pelvis in the coronal plane, were evaluated as kinematic factors.

\section{Statistical analysis}

Statistical analysis was performed using SPSS 16.0J. Comparisons between the pre- or postoperative surgical group and the healthy group were performed by unpaired $t$-test. For comparison of the surgical group before and after surgery, a paired $t$-test was used. The significance level was set at $P<0.05$. This study was performed after approval by the Ethics Committee C of Kitasato University School of Medicine and Hospital (C-Rin 09-535).

\section{Results}

\section{Radiographic and clinical functional evaluations}

Pre- and postoperative data from the radiographic and clinical functional evaluations are shown in Table 2. All radiographic evaluation items were significantly improved after surgery, and VAS similarly improved significantly after surgery. The total JOA Hip Score and scores for pain and ADL were also significantly improved, but there was no significant improvement in scores for the ROM of the hip or for gait function.
Table 2 Radiographic and clinical measurements

\begin{tabular}{llll}
\hline Measurement & Preoperative & Postoperative & P-value \\
\hline Central-edge angle $\left(^{\circ}\right)$ & $18.2 \pm 6.7$ & $39.3 \pm 10.0$ & $<0.01$ \\
Sharp angle $\left(^{\circ}\right)$ & $48.3 \pm 2.8$ & $37.7 \pm 8.1$ & $<0.01$ \\
Acetabular angle $\left(^{\circ}\right)$ & $20.7 \pm 4.5$ & $10.5 \pm 2.5$ & $<0.01$ \\
Acetabular Head & $64.5 \pm 8.3$ & $86.6 \pm 7.2$ & $<0.01$ \\
Index (\%) & & & \\
JOA Hip Score (points) & & & \\
$\quad$ Total & $67.0 \pm 19.1$ & $91.3 \pm 2.8$ & $<0.05$ \\
$\quad$ Pain & $19.2 \pm 10.2$ & $38.3 \pm 2.4$ & $<0.05$ \\
$\quad$ ROM & $18.7 \pm 2.2$ & $19.0 \pm 0.6$ & 0.75 \\
$\quad$ Gait & $14.8 \pm 3.6$ & $14.3 \pm 3.7$ & 0.62 \\
$\quad$ ADL & $14.3 \pm 4.1$ & $19.7 \pm 0.7$ & $<0.05$ \\
Visual Analog Scale $(\mathrm{cm})$ & $6.9 \pm 2.0$ & $0.6 \pm 0.8$ & $<0.01$ \\
\hline
\end{tabular}

Note: Values are expressed as the mean \pm SD.

Abbreviations: JOA, Japanese Orthopaedic Association; ROM, range of motion; $A D L$, activities of daily living; $S D$, standard deviation.

\section{Gait analysis}

Gait velocity increased after surgery in the surgical group, but it was still significantly lower than that in the healthy group (Figure 1). The preoperative stride length was significantly shorter in the surgical group compared to the healthy group, but it was significantly increased after surgery; following surgery, the difference in stride length between groups became nonsignificant (Figure 1).

The ROM of the hip joint in maximum extension in the sagittal plane during walking was significantly smaller in the surgical group than in the healthy group on the operated and nonoperated sides before surgery, and the difference on the operated side remained after surgery (Figure 2). The ROM of the hip joint in the sagittal plane during walking was also significantly smaller in the surgical group than in the healthy group on both sides before surgery, but this increased after surgery and differences observed between groups became nonsignificant on both sides (Figure 2).

The range of tilting movement of the trunk during walking increased after surgery and became significantly greater than that in the healthy group (Figure 3). The range of tilting movement of the pelvic region also increased after surgery, but it was significantly smaller than that in the healthy group before and after surgery (Figure 3 ).

\section{Discussion}

The characteristics of gait of the CPO-treated patients were evaluated before and after surgery and were compared with those of healthy subjects. The postoperative evaluation was performed at an average of 7.3 months after surgery, which is relatively early for gait evaluation after osteotomy. After $\mathrm{CPO}$, the stride length, gait velocity, and ROM of the hip 

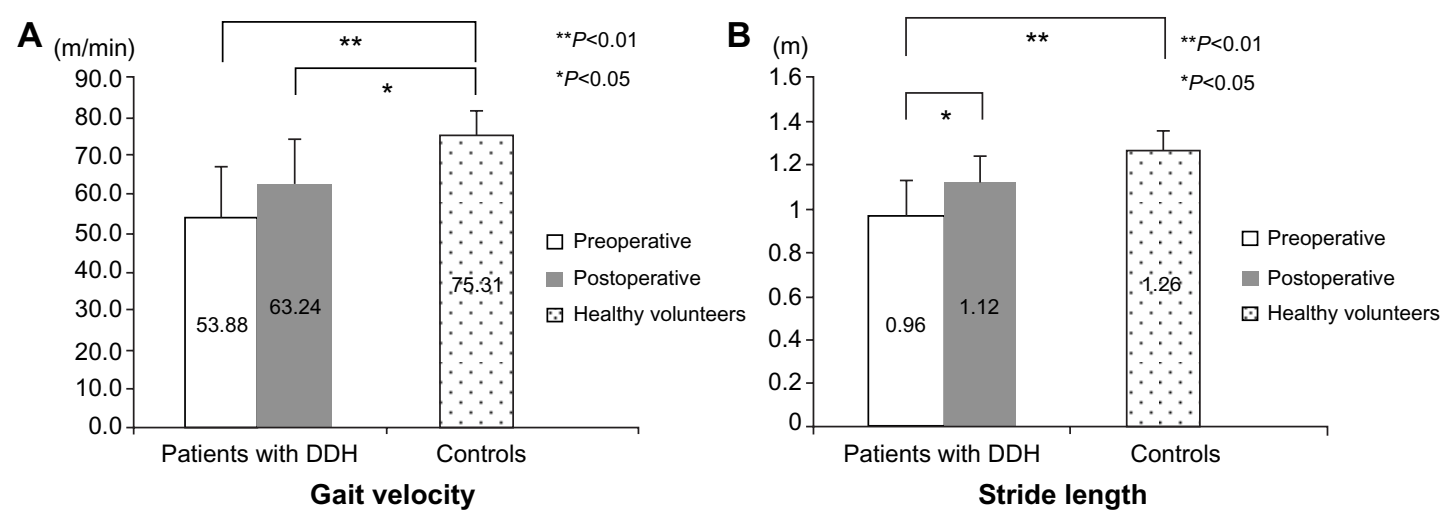

Figure I Temporospatial gait parameters of patients with DDH (pre- and postoperative) and controls.

Notes: (A) Gait velocity; (B) stride length.

Abbreviations: min, minute; $\mathrm{DDH}$, developmental dysplasia of the hip; m, meter.

joint in the sagittal plane improved, and there was also improvement of radiographic and functional items, but no improvement in the ranges of tilting movements of the trunk and pelvic region in the coronal plane.

Similar to a previous report on the surgical effect of $\mathrm{CPO}$, favorable findings were noted for radiographic factors and clinical function. ${ }^{28}$ These findings suggest that surgery was performed as planned in all patients, and that $\mathrm{AC}$ reconstruction increased coverage of the femoral head by the acetabulum, which dispersed contact pressure on the hip joint surface through leveling of the weight-bearing AC surface. In addition, dispersion of contact pressure on the hip joint surface led to the reduction of coxalgia during weight bearing and pain during walking, and ADL function was improved when compared to before surgery. In contrast, JOA Hip Scores showed no significant improvement in the ROM of the joint or in gait function. Evaluation of gait function using the JOA Hip Score is not a kinetic evaluation, but it evaluates one's ability to walk, to use a cane during walking, claudication, and the ability to walk a long distance. ${ }^{40}$ A good score requires the ability to walk for long distances and the absence of claudication. Thus, gait function based on the evaluation of clinical function is still in the recovery stage at about 7.3 months after surgery.

Patients with hip dysplasia have reduced gait velocity and step length, and an increase in the ratio of the stance phase on the healthy side. ${ }^{32,33}$ In patients treated with PAO for hip dysplasia, Karam et $\mathrm{al}^{34}$ found that stride length and gait velocity increased at an average 11.5 months after surgery, compared to those observed before surgery. The findings in the current study were similar to these results. Since our evaluation was performed at an average of 7.3 months after surgery, this comparison suggests that gait velocity and stride length improve earlier in CPO-treated patients, which may

Healthy volunteers

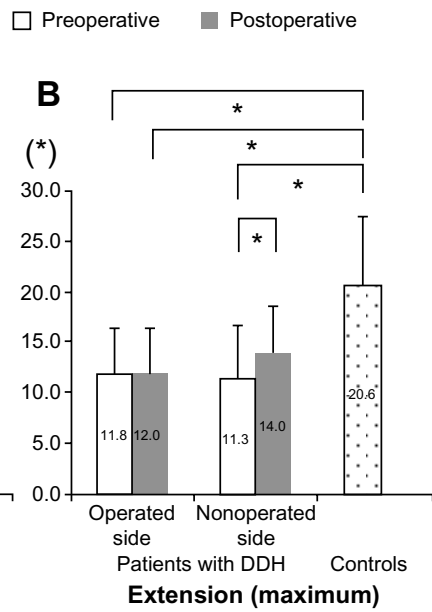

${ }^{*} P<0.05$
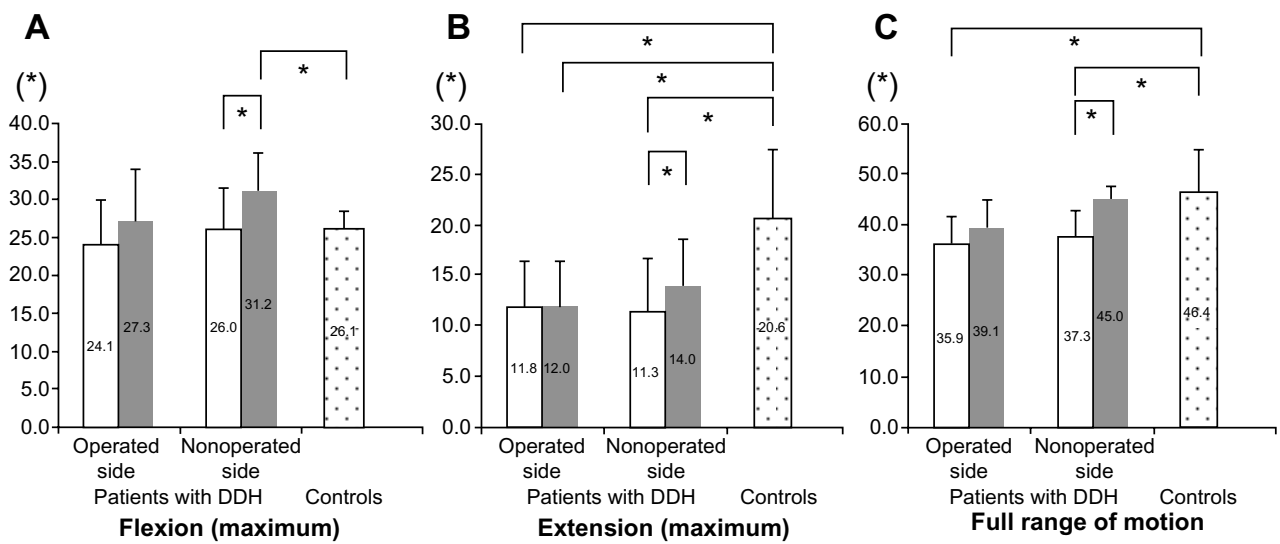

Figure 2 Sagittal hip motion angle of patients with DDH (pre- and postoperative) and controls.

Notes: (A) Flexion; (B) extension; (C) full range of motion.

Abbreviation: DDH, developmental dysplasia of the hip. 


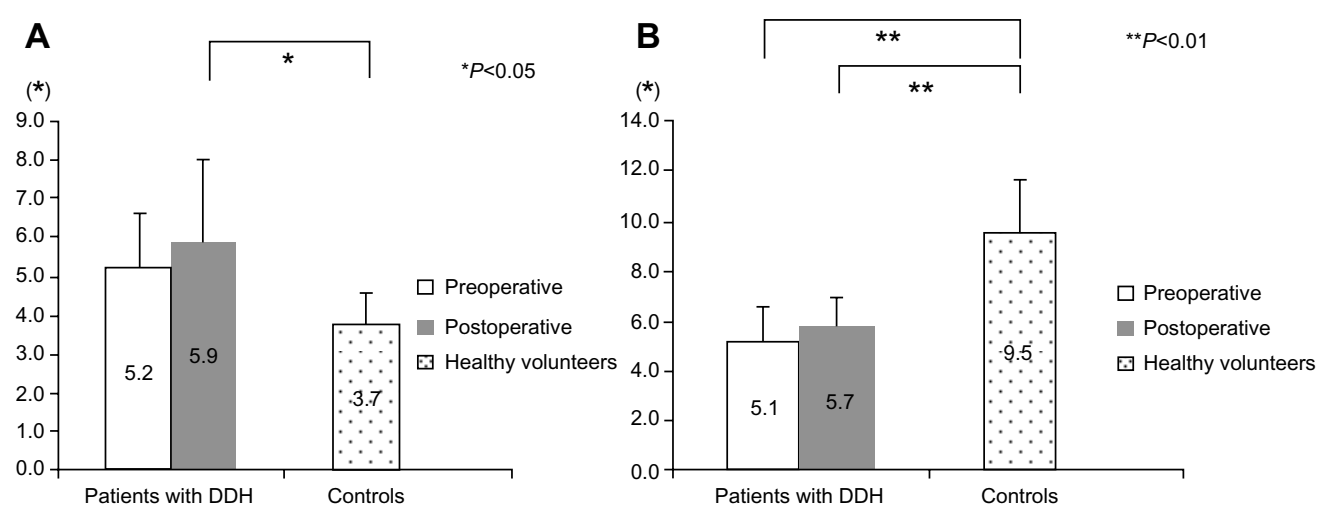

Figure 3 Frontal thoracic and pelvic motion angle of patients with DDH (pre- and postoperative) and controls.

Notes: (A) Frontal thoracic motion angle; (B) pelvis motion angle.

Abbreviation: DDH, developmental dysplasia of the hip.

be due to alleviation of coxalgia by dispersion of contact pressure by AC reconstruction and the improvement of ROM by an increase in coverage by the acetabula. However, gait velocity was still significantly slower than that of healthy subjects, despite the increase after surgery.

Before surgery, the ROM of the hip joint in the sagittal plane during walking was significantly smaller on the operated $\left(35.9^{\circ}\right)$ and nonoperated $\left(37.3^{\circ}\right)$ sides compared to that in the healthy group $\left(46.4^{\circ}\right)$. After surgery, the ROM increased on both sides $\left(39.1^{\circ}\right.$ [operated] and $45.0^{\circ}$ [nonoperated]), and the difference from the healthy group was not significant. Murray et $\mathrm{al}^{35}$ suggested that the reduced ROM of hip joint extension during walking in patients with coxalgia may result from pain-avoiding movements, thus reducing the load on the hip joint. Endo et $\mathrm{al}^{38}$ found an increase in the ROM of hip joint extension after surgery in the gait analysis of RAOtreated patients in whom the affected side had a reduced ROM before surgery compared to that in a healthy group. The preoperative ROM of hip joint extension on the operated side $\left(11.8^{\circ}\right)$ was also significantly smaller than that in the healthy group $\left(20.6^{\circ}\right)$ in our study, but no increase was obtained after surgery $\left(12.0^{\circ}\right)$, despite favorable pain relief after surgery. The ROM of the hip in the sagittal plane on the nonoperated side was decreased before surgery. This may have been due to severe coxalgia on the operated side before surgery and fear of aggravation of this pain. The postoperative results for clinical function suggested that preoperative anxiety regarding pain during walking was resolved with improvement of coxalgia on the operated side, which increased the ROM of the hip in the sagittal plane on the nonoperated side.

Differences in evaluation timing may account for these contradictory results. In previous studies, gait after osteotomy has been evaluated at an average of 11-18 months after surgery, including in the Endo et al study. ${ }^{34,37,38}$ Thus, our evaluation at an average of 7.3 months after surgery was earlier than that in any previous report. In addition, Queen et $\mathrm{al}^{36}$ observed a limited ROM of hip joint extension during walking in pre- and postoperative gait analyses in THAtreated patients, and suggested that this may have been due to contracture of soft tissue, such as the articular capsule and hip flexors, induced by insufficient long-term use of the affected limb, including the hip joint. In rehabilitation for patients treated with $\mathrm{AC}$ osteotomy such as $\mathrm{CPO}, \mathrm{RAO}$, and $\mathrm{PAO}$, the duration of nonweight-bearing walking using a Lofstrand crutch and T-shape cane is generally long, prolonging the period before free gait without a walking aid is allowed, and patients refrain from loading a weight on the affected leg as much as possible during this period. The duration of this period was about 4-6 months in this study. Therefore, the time may have been insufficient for improvement of soft tissue contracture around the hip joint and recovery from limited hip joint extension. Since residual limitation of hip joint extension reduces the propulsive force for forward walking, this may have led to insufficient recovery of gait velocity. The increase in the ROM of hip joint flexion during walking from $24.1^{\circ}$ before surgery to $27.3^{\circ}$ after surgery in our study may have been due to compensation for this limited extension.

Lateral sway of the trunk during walking (Duchenne claudication) is a characteristic of claudication of patients with hip joint disorders. ${ }^{30,31}$ The range of tilting movement of the trunk in the coronal plane during walking was increased before surgery $\left(5.2^{\circ}\right)$, although not significantly compared to the healthy group $\left(3.7^{\circ}\right)$, and it further increased after surgery $\left(5.9^{\circ}\right)$ and showed a significant difference from the healthy group. Reininga et $\mathrm{al}^{43}$ obtained similar findings in a comparison of trunk movement during walking using a body sensor in patients with osteoarthritis of the hip and 
healthy subjects. Trunk sway during walking is caused by a compensatory action to reduce pain by increasing coverage of the femoral head and reducing weight bearing on the hip joint by tilting the trunk toward the affected side in the stance phase of the affected side. ${ }^{31,44}$ This compensatory action also induces weakening of the abductor muscle of the hip. ${ }^{45}$ Thus, the increased range of tilting movement of the trunk before surgery in our patients may have been due to compensatory movement to reduce pain and a weakened abductor muscle. The slight increase in the range of tilting movement of the trunk after surgery indicates that the procedure did not have a favorable outcome soon after surgery with regard to trunk sway during walking.

Ezoe et $\mathrm{al}^{46}$ evaluated the strength of muscles of the hip (flexor, extensor, abductor, and adductor) before and after surgery in CPO-treated patients, and found that the strength compared to that before surgery was decreased at 6 months after surgery, but it had increased at 12 months. Since we evaluated gait at an average of 7.3 months after surgery, the strength of the abductor muscle of the hip may not have sufficiently recovered. This time point resulted from specifying the time of analysis as that of progression from cane-assisted gait to independent gait without a cane. The patients used a cane in their daily life until the postoperative evaluation, and thus had adapted to gait motion using a cane. Use of a cane during walking prevents center of gravity sway without breaking the balance, and it reduces load on the affected limb. ${ }^{47,48}$ Since patients who had adapted to cane-assisted gait suddenly had to walk without a cane, they may not have been able to maintain balance to prevent center of gravity sway, which was previously assisted by a cane during walking, and this may have led to trunk sway. Ajemian et $\mathrm{al}^{49}$ found a reduction of the hip joint abduction moment on the affected side during walking in patients walking with a cane after THA, and Maguire et $\mathrm{al}^{50}$ observed a reduction of abductor muscle activity on the noncane-assisted side in a study of the hip abductor muscle during use of a cane in stroke patients. Based on these reports, long-term cane-assisted gait may have caused hip abductor muscle dysfunction in our patients. The hip abductor muscle stabilizes the pelvic region in the stance phase of the walking cycle and prevents center of gravity sway during walking. This function may not have recovered soon after surgery, resulting in the increase in trunk sway during walking.

There are several limitations in the study. Firstly, the evaluation time point may have been too early compared to previous gait analyses performed after AC osteotomy. However, there are several advantages in early gait analysis: motor function in ADL after surgery can be evaluated earlier; the influence of long-term cane-assisted gait after surgery on walking motion can be identified; and objective information can be obtained and used as feedback for rehabilitation at an outpatient clinic or at home. Secondly, cane-assisted gait was not analyzed. The patients had to walk without a cane during the measurement, although they had adapted to a cane-assisted gait in daily life. This condition may have influenced independent gait in the measurement, and it may be necessary to investigate the influence of canes on walking motion by analyzing gait with and without a cane. Thirdly, there were only six subjects in the surgical group and all were women, although the matching control group reduced the sex-related bias. This was because we placed priority on the physical and mental conditions of the participants, and thus tried to minimize the burden on patients by performing the gait analysis in wards, although this analysis is normally performed in a laboratory. Gait analysis was performed in the presence of a physical therapist for safety, and the study involved a single operator and measurer to minimize biases in surgery and measurement items. This may compensate for the disadvantage of the small number of subjects. However, clarification of the process of recovery of gait motion after surgery in CPO-treated patients will require the study of more subjects, and with medium- and long-term follow-up.

\section{Conclusion}

In conclusion, increases in stride length, gait velocity, and ROM of the hip joint in the sagittal plane during walking were observed as gait characteristics soon after surgery in patients treated with $\mathrm{CPO}$ for DDH. These findings suggest early improvement of forward propulsion in gait. In contrast, the range of trunk movement in the coronal plane increased after surgery, suggesting that trunk sway during walking was still in the recovery process.

\section{Disclosure}

The authors report no conflicts of interest in this work.

\section{References}

1. Jingushi S, Ohfuji S, Sofue M, et al. Multiinstitutional epidemiological study regarding osteoarthritis of the hip in Japan. J Orthop Sci. 2010;15(5):626-631.

2. Jingushi S, Ohfuji S, Sofue M, et al. Osteoarthritis hip joints in Japan: involvement of acetabular dysplasia. J Orthop Sci. 2011;16(2): $156-164$

3. Nakamura S, Ninomiya S, Nakamura T. Primary osteoarthritis of the hip joint in Japan. Clin Orthop Relat Res. 1989;(241):190-196.

4. Sucato DJ, Tulchin K, Shrader MW, DeLaRocha A, Gist T, Sheu G. Gait, hip strength and functional outcomes after a Ganz periacetabular osteotomy for adolescent hip dysplasia. J Pediatr Orthop. 2010;30(4): 344-350. 
5. Mavcic B, Iglic A, Kralj-Iglic V, Brand RA, Venqust R. Cumulative hip contact stress predicts osteoarthritis in DDH. Clin Orthop Related Res. 2008;466(4):884-891.

6. Ganz R, Leunig M. Osteotomy and the dysplastic hip: the Bernese experience. Orthopedics. 2002;25(9):945-946.

7. Murphy SB, Millis MB. Periacetabular osteotomy without abductor dissection using direct anterior exposure. Clin Orthop Relat Res. 1999;(364):92-98.

8. Murphy SB, Millis MB, Hall JE. Surgical correction of acetabular dysplasia in the adult. A Boston experience. Clin Orthop Relat Res. 1999;(363):38-44.

9. Peters CL, Erickson J. The etiology and treatment of hip pain in the young adult. J Bone Joint Surg Am. 2006;88 Suppl 4:20-26.

10. Murphy SB, Ganz R, Müller ME. The prognosis in untreated dysplasia of the hip. A study of radiographic factors that predict the outcome. J Bone Joint Surg Am. 1995;77(7):985-989.

11. Millis MB, Poss R, Murphy SB. Osteotomies of the hip in the prevention and treatment of osteoarthritis. Instr Course Lect. 1992;41 $145-154$.

12. Murphy SB, Kijewski PK, Millis MB, Harless A. Acetabular dysplasia in the adolescent and young adult. Clin Orthop Relat Res. 1990;(261): 214-223.

13. Harris WH. Etiology of osteoarthritis of the hip. Clin Orthop Relat Res. 1986;(213):20-33.

14. Cooperman DR, Wallensten R, Stulberg SD. Acetabular dysplasia in the adult. Clin Orthop Relat Res. 1983;(175):79-85.

15. Ganz R, Klaue K, Vinh TS, Mast JW. A new periacetabular osteotomy for the treatment of hip dysplasias. Technique and preliminary results. Clin Orthop Relat Res. 1988;(232):26-36.

16. Clohisy JC, Barrett SE, Gordon JE, Delgado ED, Schoenecker PL. Periacetabular osteotomy in the treatment of severe acetabular dysplasia. Surgical technique. J Bone Joint Surg Am. 2006;88 Suppl 1 Pt 1: 65-83.

17. Peters CL, Erickson JA, Hines JL. Early results of the Bernese periacetabular osteotomy: the learning curve at an academic medical center. J Bone Joint Surg Am. 2006;88(9):1920-1926.

18. Trousdale RT, Cabanela ME. Lessons learned after more than 250 periacetabular osteotomies. Acta Orthop Scand. 2003;74(2) 119-126.

19. Leunig M, Siebenrock KA, Ganz R. Rationale of periacetabular osteotomy and background work. Instr Course Lect. 2001;50: 229-238.

20. Siebenrock KA, Schöll E, Lottenbach M, Ganz R. Bernese periacetabular osteotomy. Clin Orthop Relat Res. 1999;(363):9-20.

21. Trousdale RT, Ekkernkamp A, Ganz R, Wallrichs SL. Periacetabular and intertrochanteric osteotomy for the treatment of osteoarthrosis in dysplastic hips. J Bone Joint Surg Am. 1995;77(1):73-85.

22. Steppacher SD, Tannast M, Ganz R, Siebenrock KA. Mean 20-year followup of Bernese periacetabular osteotomy. Clin Orthop Relat Res. 2008;466(7):1633-1644.

23. Kralj M, Mavcic B, Antolic V, Iglic A, Kralj-Iglic V. The Bernese periacetabular osteotomy: clinical, radiographic and mechanical 7-15-year follow-up of 26 hips. Acta Orthop. 2005;76(6):833-840.

24. Hickman JM, Peters CL. Hip pain in the young adult: diagnosis and treatment of disorders of the acetabular labrum and acetabular dysplasia. Am J Orthop (Belle Mead NJ). 2001;30(6):459-467.

25. Crockarell J Jr, Trousdale RT, Cabanela ME, Berry DJ. Early experience and results with the periacetabular osteotomy. The Mayo Clinic experience. Clin Orthop Relat Res. 1999;(363):45-53.

26. Matta JM, Stover MD, Siebenrock K. Periacetabular osteotomy through the Smith-Petersen approach. Clin Orthop Relat Res. 1999;(363): 21-32.

27. Davey JP, Santore RF. Complications of periacetabular osteotomy. Clin Orthop Relat Res. 1999;(363):33-37.

28. Naito M, Shiramizu K, Akiyoshi Y, Ezoe M, Nakamura Y. Curved periacetabular osteotomy for treatment of dysplastic hip. Clin Orthop Relat Res. 2005;(433):129-135.
29. Shiramizu K, Naito M, Asayama I, Yatsunami M. Curved periacetabular osteotomy for the dysplastic hip: cadaveric and radiological analyses of safe procedures. Journal of Orthopaedics and Traumatology. 2003;4:55-60.

30. Buckup K. Clinical Tests for the Musculoskeletal System: Examinations-Signs-Phenomena. Stuttgart, Germany: Georg Thieme Verlag; 2004.

31. Patrick JH, van Niekerk L. Orthopedic assessment of gait disorders. In: Bronstein AM, Brandt T, Woollacott MH, Nutt JG, editors. Clinical Disorders of Balance, Posture and Gait. 2nd ed. London, UK: Arnold; 2004:74-92.

32. Romanò CL, Frigo C, Randelli G, Pedotti A. Analysis of the gait of adults who had residua of congenital dysplasia of the hip. $J$ Bone Joint Surg Am. 1996;78(10):1468-1479.

33. Lai KA, Lin CJ, Su FC. Gait analysis of adult patients with complete congenital dislocation of the hip. J Formos Med Assoc. 1997;96(9): 740-744.

34. Karam MD, Gao Y, McKinley T. Assessment of walking pattern pre and post peri-acetabular osteotomy. Iowa Orthop J. 2011;31:83-89.

35. Murray MP, Gore DR, Clarkson BH. Walking patterns of patients with unilateral hip pain due to osteo-arthritis and avascular necrosis. $J$ Bone Joint Surg Am. 1971;53(2):259-274.

36. Queen RM, Butler RJ, Watters TS, Kelley SS, Attarian DE, Bolognesi MP. The effect of total hip arthroplasty surgical approach on postoperative gait mechanics. J Arthroplasty. 2011;26(6 Suppl):66-71.

37. Pedersen EN, Alkjaer T, Søballe K, Simonsen EB. Walking pattern in 9 women with hip dysplasia 18 months after periacetabular osteotomy. Acta Orthop. 2006;77(2):203-208.

38. Endo H, Mitani S, Senda M, et al. Three-dimensional gait analysis of adults with hip dysplasia after rotational acetabular osteotomy. J Orthop Sci. 2003;8(6):762-771.

39. Ninomiya S, Tagawa H. Rotational acetabular osteotomy for the dysplastic hip. J Bone Joint Surg Am. 1984;66(3):430-436.

40. Imura S. Evaluation chart of hip joint functions. Journal of the Japanese Orthopaedic Association. 1995;69:864-867.

41. Schache AG, Blanch PD, Rath DA, Wrigley TV, Starr R, Bennell KL. Intra-subject repeatability of the three dimensional angular kinematics within the lumbo-pelvic-hip complex during running. Gait Posture. 2002;15(2):136-145.

42. Franz JR, Paylo KW, Dicharry J, Riley PO, Kerrigan DC. Changes in the coordination of hip and pelvis kinematics with mode of locomotion. Gait Posture. 2009;29(3):494-498.

43. Reininga IH, Stevens M, Wagenmakers R, Bulstra SK, Groothoff JW, Zijlstra W. Subjects with hip osteoarthritis show distinctive patterns of trunk movements during gait-a body-fixed-sensor based analysis. J Neuroeng Rehabil. 2012;9:3.

44. Watelain E, Dujardin F, Babier F, Dubois D, Allard P. Pelvic and lower limb compensatory actions of subjects in an early stage of hip osteoarthritis. Arch Phys Med Rehabil. 2001;82(12):1705-1711.

45. Rasch A, Byström AH, Dalen N, Berg HE. Reduced muscle radiological density, cross-sectional area, and strength of major hip and knee muscles in 22 patients with hip osteoarthritis. Acta Orthop. 2007;78(4): 505-510.

46. Ezoe M, Naito M, Asayama I. Muscle strength improves after abductor-sparing periacetabular osteotomy. Clin Orthop Relat Res. 2006;444:161-168.

47. Neumann DA. Biomechanical analysis of selected principles of hip joint protection. Arthritis Care Res. 1989;2(4):146-155.

48. Bateni H, Maki BE. Assistive devices for balance and mobility: benefits, demands, and adverse consequences. Arch Phys Med Rehabil. 2005;86(1):134-145.

49. Ajemian S, Thon D, Clare P, Kaul L, Zernicke RF, Loitz-Ramage B. Cane-assisted gait biomechanics and electromyography after total hip arthroplasty. Arch Phys Med Rehabil. 2004;85(12):1966-1971.

50. Maguire C, Sieben JM, Frank M, Romkes J. Hip abductor control in walking following stroke - the immediate effect of canes, taping and TheraTogs on gait. Clin Rehabil. 2010;24(1):37-45. 
Orthopedic Research and Reviews

Dovepress

\section{Publish your work in this journal}

Orthopedic Research and Reviews is an international, peer-reviewed, open access journal focusing on the patho-physiology of the musculoskeletal system, trauma, surgery and other corrective interventions to restore mobility and function. Advances in new technologies, materials, techniques and pharmacological agents are particularly welcome. The journal welcomes

original research, clinical studies, reviews \& evaluations, expert opinion and commentary, case reports and extended reports. The manuscript management system is completely online and includes a very quick and fair peer-review system, which is all easy to use. Visit http://www.dovepress. com/testimonials.php to read real quotes from published authors.

Submit your manuscript here: http://www.dovepress.com/orthopedic-research-and-reviews-journal 